\title{
Nondysraphic Intramedullary Cervical Cord Lipoma with Exophytic Component: Case Report
}

\author{
1 Department of Neurosurgery, Louisiana State University Health \\ Sciences Center, Shreveport, Louisiana, United States \\ 2 Department of Neurosurgery, Louisiana State University Health \\ Sciences Center, Shreveport, Louisiana, United States
}

Osama Ahmed ${ }^{1}$ Shihao Zhang ${ }^{1}$ Jai Deep Thakur ${ }^{1}$ Anil Nanda ${ }^{2}$

\begin{abstract}
Address for correspondence Osama Ahmed, MD, Department of Neurosurgery, Louisiana State University Health Sciences Center, 1501 Kings Highway, Shreveport, LA 71103, United States (e-mail: oahmed@Isuhsc.edu).
\end{abstract}

J Neurol Surg Rep 2015;76:e87-e90.

\begin{abstract}
Keywords

- intramedullary spinal cord neoplasm

- lipoma

- cervical cord neoplasm

Introduction Spinal intradural lipoma is a rare condition, accounting for $<1 \%$ of all spinal cord tumors. Spinal cord lipomas are frequently associated with dysraphism and occur in the thoracic spine. Another common finding is that spinal cord lipomas tend to present in the pediatric population. Isolated nondysraphic cervical lipomas are a rare entity. We discuss a case of nondysraphic cervical lipoma with an exophytic component. Case A 31 year-old woman presented with bilateral numbness in her hands and a burning and aching sensation in her arms for $\sim 6$ months. The patient did not have any weakness or myelopathic signs. Magnetic resonance imaging T1 showed a T1 hyperintense, $\mathrm{T} 2$ hypointense, non-contrast-enhancing mass on the dorsal aspect of the spinal cord with significant compression. The patient underwent a dorsal cervical laminectomy with subtotal resection of an isolated cervical lipoma with an exophytic component. The pathology confirmed the diagnosis of a lipoma.

Conclusions Surgical management of this rare pathology has a wide variety of options. Depending on the neurologic deficits, observation to gross total resection may be reasonable options. In our case, a subtotal resection was achieved with no further worsening of neurologic symptoms.
\end{abstract}

\section{Introduction}

Spinal intradural lipoma is a rare condition, accounting for $<1 \%$ of all spinal cord tumors. ${ }^{1}$ When encountered, most are found in the lumbosacral region with coinciding spinal dysraphism. Several reports in the literature have discussed spinal cord lipomas, especially in the pediatric population; however, there are fewer reports of isolated cervical cord lipomas. A rarer occurrence is a nondysraphic lipoma of the cervical cord. Nondysraphic spinal cord lipomas usually present in the second or third decade of life, representing 55\% of the cases. These usually present in the thoracic spine, followed by the cervicothoracic junction. Only $12 \%$ of these tumors are localized to the cervical spine. $^{2,3}$ We discuss a case of a nondysraphic cervical lipoma with an exophytic component in an adult.

\section{Case Report}

A 31-year-old white woman presented with bilateral numbness in her hands. The patient also described bilateral burning and an aching sensation in her arms. The numbness began $\sim 6$ months prior to presenting at the clinic. Symptoms were periodic but were getting progressively worse. The numbness was noted to be worse in the right hand. Approximately 3 months before presentation, the patient noted some neck stiffness and pain. She started noticing some weakness developing in her hands. The patient had a significant history of bilateral carpel tunnel release.

Physical examination showed the patient had a good range of motion in her neck, intact muscle strength in all groups, good muscle tone, normal reflexes, and no myelopathic signs. She did
August 5, 2014

accepted

December 16, 2014

published online

May 13, 2015
DOI http://dx.doi.org/

10.1055/s-0035-1547367. ISSN 2193-6366.
License terms (c) 2015 Georg Thieme Verlag KG
Stuttgart · New York

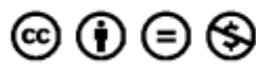


not have any gait disturbances. Radiographic work-up revealed a $2.54 \times 1 \mathrm{~cm}$ hyperintense lesion on $\mathrm{T} 1$ with $\sim 40 \%$ cord compression. The lesion spanned the entire length of the C6 vertebral body and $75 \%$ of the $\mathrm{C} 7$ vertebral body. The lesion was isointense on $\mathrm{T} 2$ with no contrast uptake noted. There was a heterogenic component to this lesion at the level of the C6-C7 disk that may have indicated an infiltrative process (- Figs. 1-6).

The patient was taken to the operating room for a posterior cervical laminectomy and resection of the mass. She was placed in a prone position with electrophysiologic monitoring. A posterior cervical midline incision was made from $\mathrm{C} 5$ to C7. After a subperiosteal dissection, we used a high-speed drill to create troughs bilaterally. The lamina was removed en bloc, hoping to secure the lamina after the tumor resection with laminoplasty trough plates.

A midline durotomy was performed, spanning both the cephalad and caudal poles of the tumor. On gross inspection of the tumor, the tumor was yellow and ellipsoid, involving both extramedullary and intramedullary components (-Fig. 7). With microscopic evaluation, we determined that a gross total resection of this tumor might not be possible due to the involvement of the spinal cord. We began to resect layers of the tumor in a dorsal to ventral fashion. As we approached the spinal cord, it was deemed the remaining portion of the tumor was unresectable ( - Fig. 8). We secured the en bloc lamina with laminoplasty trough plates. We used a small amount of Progenix (Medtronic Spinal and Biologics, Memphis, Tennessee, United States) in the lateral gutters to aid in bony regrowth. The patient woke up without any new neurologic deficits. Postoperatively, the patient had no significant improvement in her sensory deficits. The pathology specimen was reviewed by a neuropathologist, and the diagnosis was a lipoma.

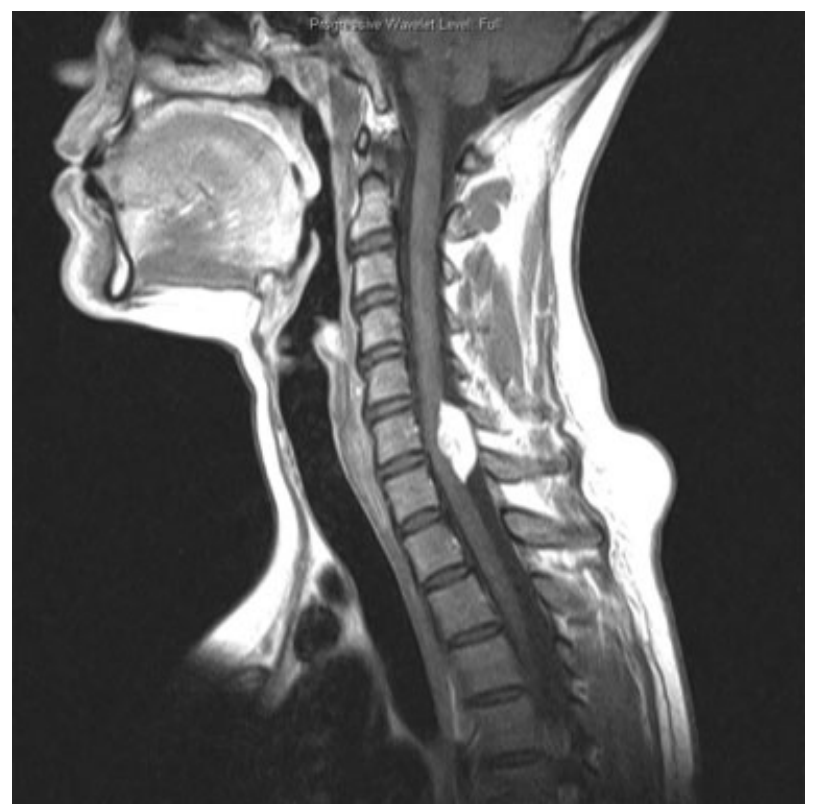

Fig. 1 A sagittal view, T1 with contrast, of the cervical spine.

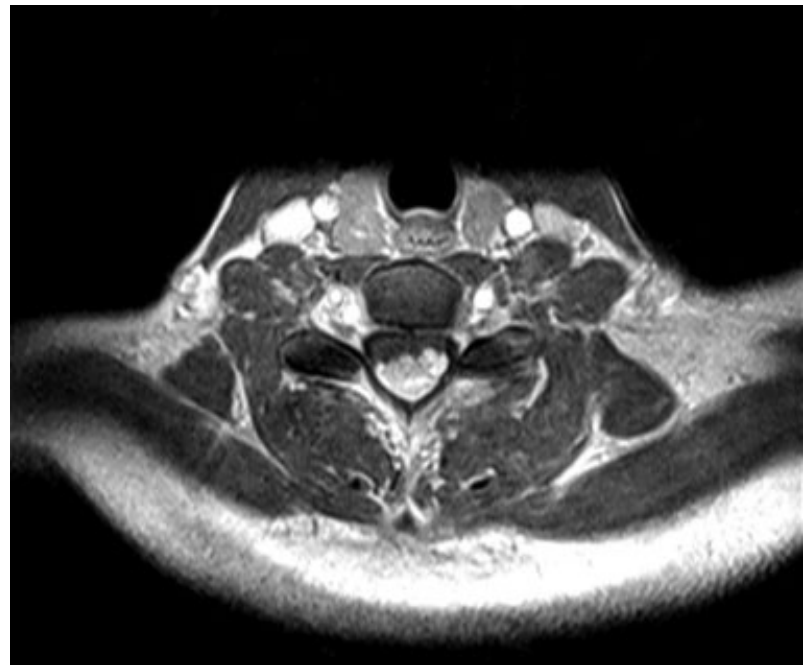

Fig. 2 An axial view, T1 with contrast, of the cervical spine.

The patient has been followed up for 1 year now. There is no worsening or improvement in her symptoms. The patient does not exhibit any muscle weakness or myelopathic signs.

\section{Discussion}

It is well reported in the literature that spinal cord lipomas compromise $<1 \%$ of all spinal cord tumors. ${ }^{1}$ They are located dorsally and may have an exophytic component. Hydromyelia is present in $\sim 2 \%$ of the cases but was not present in this case. Dysraphism may include vertebral body anomalies, widening of the spinal canal and neural foramina, or anomalies of the posterior elements of the spine. ${ }^{4}$ Uncertainty exists in the literature whether these lipomas are true neoplasms or hamartomas. The behavioral characteristic of this lesion may lie in the origin. There are reports of nondysraphic

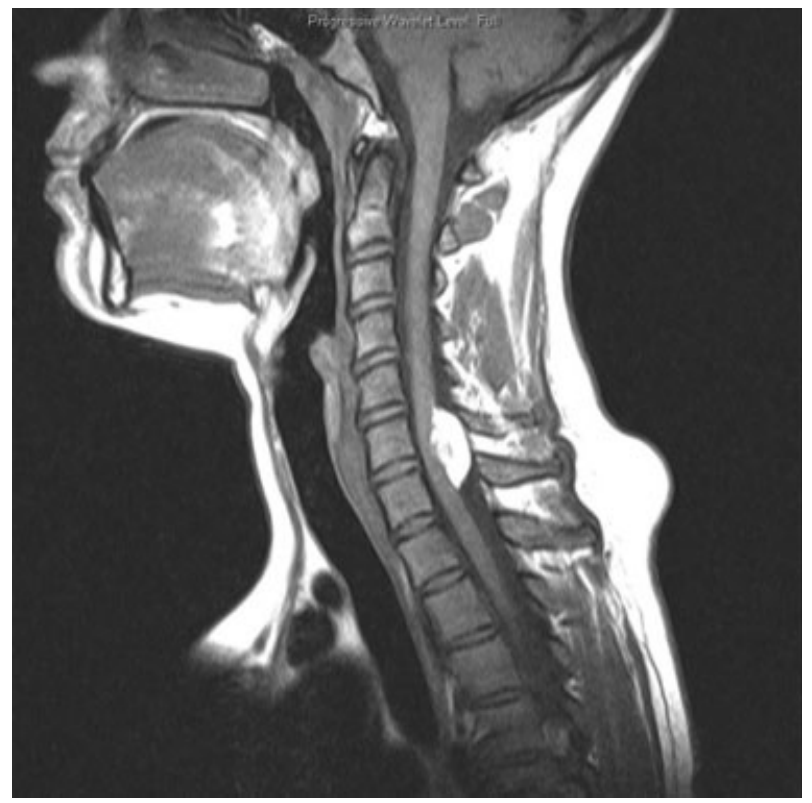

Fig. 3 A sagittal view, $\mathrm{T} 1$ without contrast, of the cervical spine. There is a hyperintense, non-contrast-enhancing mass on the dorsal aspect of the spinal cord causing cord compression. 


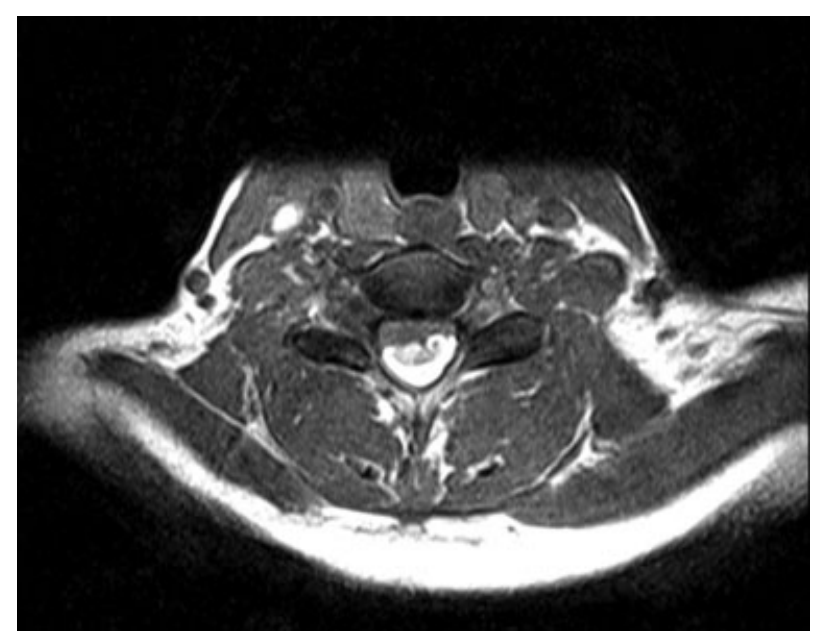

Fig. 4 An axial view, T1 without contrast, of the cervical spine. There is a hyperintense, non-contrast-enhancing mass on the dorsal aspect of the spinal cord causing cord compression.

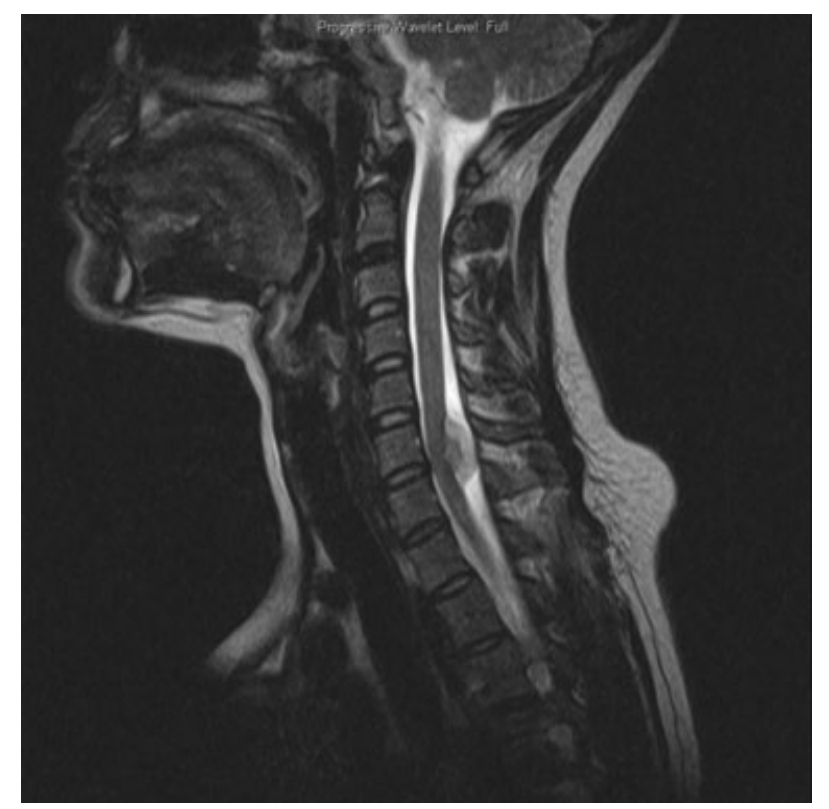

Fig. 5 A sagittal, T2 view. The mass measured to be $\sim 2.54 \times 1 \mathrm{~cm}$.

lipoma recurring after resection due to hyperplasia, which supports it being a true neoplasm. Dysraphic lipomas are believed to be hamartomas. ${ }^{5}$

Spinal cord lipomas are more frequently encountered in the pediatric population, possibly due to their embryological origin. Depending on the location and involvement of neural structures, lipomas can present with a wide variety of symptoms. Mild neurologic dysfunction, such as sensory deficits, can be an indolent-presenting symptom for years. Other symptoms include growth retardation, dysphagia, respiratory difficulty, gait problems, and paresis ( the most common). ${ }^{6-8}$

Lipomas consist of mature adipocytes with no atypical cellular features. These cells lie in fibrous connective tissue. Striated muscle, epithelial derivatives, bone, and neural tissue may also be found within lipomas. In our case, neural structures were involved on gross inspection, and adipocytes were

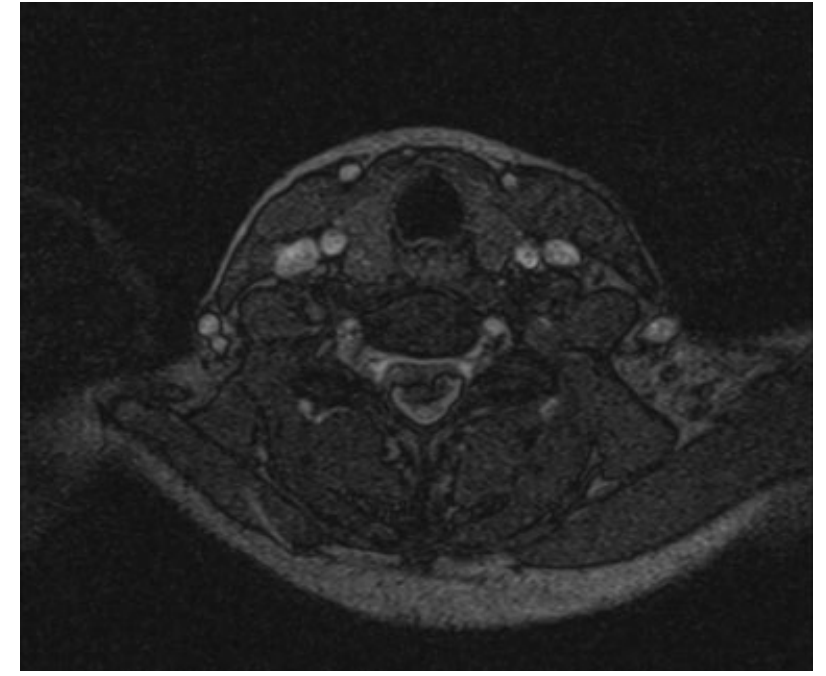

Fig. 6 An axial, T2 view. The mass measured to be $\sim 2.54 \times 1 \mathrm{~cm}$.

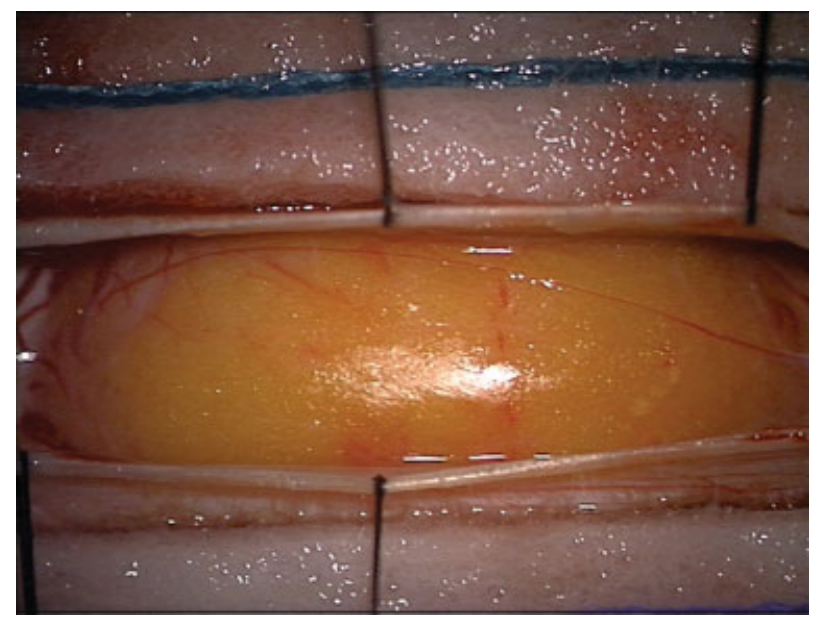

Fig. 7 The dorsal aspect of the tumor after the laminectomy and midline durotomy are performed. These intraoperative pictures show the tumor.

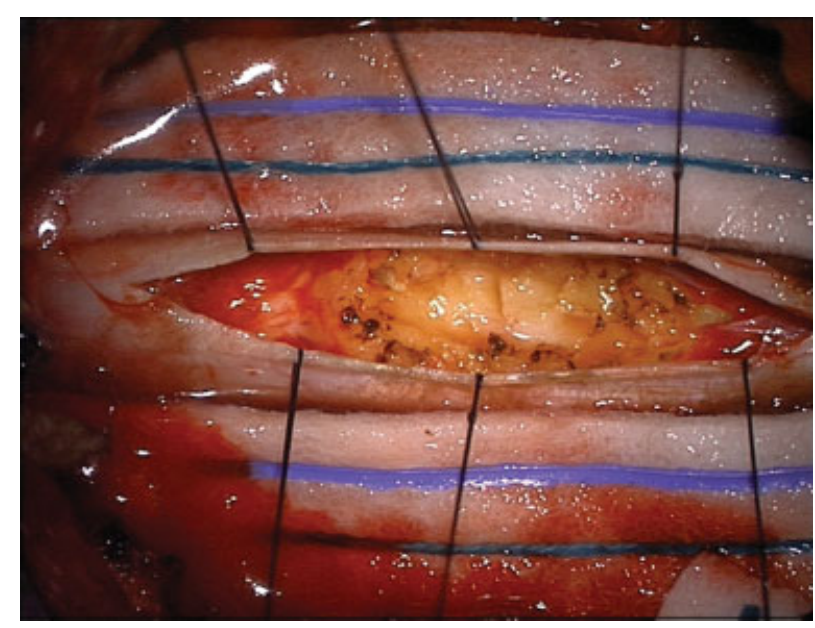

Fig. 8 The tumor after part of the exophytic portion was removed. These intraoperative pictures show the tumor. Left: cranial; right: caudal; down: left; up: right. 
the only cells present on microscopic inspection. Lipomas are believed to change in size as body fat content changes. It is also believed that patients with a large body fat content are predisposed to developing lipomas. In our case, we did not recommend weight loss as a conservative treatment option because the patient was of normal weight. ${ }^{9}$ Grossly, lipomas have historically been found to easily separate at the tips of the lesion; the intraparenchymal margins are adherent. ${ }^{10}$ In our case, all margins of the tumor were adherent and embedded within the spinal cord.

Magnetic resonance imaging is the best imaging modality for this tumor. Fat is hyperintense on T1 with no increased contrast uptake and hypointense on T2. Although other pathologies can have similar characteristics on MRI, a fat suppression sequence can help delineate a lipoma from blood or calcifications. ${ }^{10,11}$

There are several theories on the developmental mechanism of spinal cord lipomas. Most theories contribute the development of dysraphic spinal cord lipomas to an adipocyte migration problem during embryological development. ${ }^{12}$ One hypothesis is that if the neuroectoderm does not close properly, the mesoderm that migrates between the cutaneous and neural ectoderm can extend to the dorsal surface of the incompletely closed neuroectoderm. ${ }^{13}$ Another theory is that premature detachment of the neural tube allows the neuroectoderm to fold in, allowing mesenchymal cells in the dorsal aspect of the cord. The ingrowth of mesenchymal tissue is the cause of spinal dysraphism. ${ }^{14}$ Unfortunately, the pathogenesis of nondysraphic spinal cord lipomas is unclear.

Surgical management of spinal cord lipomas is controversial. Treatment options include observation, spinal cord decompression, biopsy, subtotal resection, and gross total resection. Varying clinical scenarios may warrant different treatment options. If severe neurologic deficits are observed, decompression with an attempt at resection may be the treatment of choice. Gross total resection may prove to be technically challenging because most of these lipomas are adherent to the spinal cord and do not have a true plane for dissection. ${ }^{5}$ If the lipoma is found incidentally, observation may be sufficient. Due to their benign nature, early literature advocates for conservative treatment measures; others argue for a subtotal resection. ${ }^{15,16}$ Functional improvement is anticipated after cord decompression due to their indolent behavior; however, the adherent nature may cause an intrinsic component of neurologic dysfunction. ${ }^{17}$

\section{Conclusion}

We report a rare case of a cervical cord lipoma in an adult. There is literature that discusses this pathology; however, nondysraphic lipoma was isolated to the cervical cord with an exophytic component. A wide variety of treatment options are available with these tumors. The degree of neurologic dysfunction indicates the aggressiveness of treatment.

\section{References}

1 Drapkin AJ. High cervical intradural lipoma. J Neurosurg 1974; 41(6):699-704

2 Giuffrè R. Intradural spinal lipomas. Review of the literature (99 cases) and report of an additional case. Acta Neurochir (Wien) 1966;14(1):69-95 (Wien)

3 Lantos G, Epstein F, Kory LA. Magnetic resonance imaging of intradural spinal lipoma. Neurosurgery 1987;20(3):469-472

4 Mrabet A, Zouari R, Mouelhi T, et al. Cervicobulbar intramedullary lipoma. Apropos of a case with review of the literature [in French]. Neurochirurgie 1992;38(5):309-314

5 Fleming KL, Davidson L, Gonzalez-Gomez I, McComb JG. Nondysraphic pediatric intramedullary spinal cord lipomas: report of 5 cases. J Neurosurg Pediatr 2010;5(2):172-178

6 Kai Y, Amano T, Inamura T, et al. An infant with an intradural lipoma of the cervical spine extending into the posterior fossa. J Clin Neurosci 2003;10(1):127-130

7 Kogler A, Orsolic K, Kogler V. Intramedullary lipoma of dorsocervicothoracic spinal cord with intracranial extension and hydrocephalus. Pediatr Neurosurg 1998;28(5):257-260

8 Naim-ur-Rahman, Shahat AH, Obaideen AM, Ahmed K, Ahmed S. Intramedullary lipoma of the cervicodorsal spinal cord with intracranial extension: case report. Surg Neurol 2006;65(5): 486-489

9 Mohindra S, Gupta SK. Cervicobulbar intramedullary lipoma. Spine J 2009;9(3):e12-e16

10 Kamel HA, Brennan PR, Farrell MA. Cervical epidural lipoblastomatosis: changing MR appearance after chemotherapy. AJNR Am J Neuroradiol 1999;20(3):386-389

11 Iwatsuki K. Intradural cervical lipoma with parenchymal marginal fibrous tissue: case report. Neurosurgery 2006;59(1):E208-E209; discussion E208

$12 \mathrm{Kim} \mathrm{CH}$, Wang KC, Kim SK, et al. Spinal intramedullary lipoma: report of three cases. Spinal Cord 2003;41(5):310-315

13 Bhatoe HS, Singh P, Chaturvedi A, Sahai K, Dutta V, Sahoo PK. Nondysraphic intramedullary spinal cord lipomas: a review. Neurosurg Focus 2005;18(2):ECP1

14 Naidich TP, McLone DG, Mutluer S. A new understanding of dorsal dysraphism with lipoma (lipomyeloschisis): radiologic evaluation and surgical correction. AJR Am J Roentgenol 1983;140(6): 1065-1078

15 Dillon WP, Norman D, Newton TH, Bolla K, Mark A. Intradural spinal cord lesions: Gd-DTPA-enhanced MR imaging. Radiology 1989;170(1 Pt 1):229-237

16 Fetsch JF, Miettinen M, Laskin WB, Michal M, Enzinger FM. A clinicopathologic study of 45 pediatric soft tissue tumors with an admixture of adipose tissue and fibroblastic elements, and a proposal for classification as lipofibromatosis. Am J Surg Pathol 2000;24(11):1491-1500

17 Le Feuvre DEJ, Semple PL, Peter JC. Intradural cervical lipomas with intracranial extension: a management strategy based on a case report and review of the literature. Br J Neurosurg 2004;18(4): 385-388 